\title{
Two months of disdrometer data in the Paris area
}

\author{
Auguste Gires, Ioulia Tchiguirinskaia, and Daniel Schertzer \\ HM\&Co, École des Ponts, UPE, Champs-sur-Marne, France \\ Correspondence: Auguste Gires (auguste.gires@enpc.fr)
}

Received: 22 December 2017 - Discussion started: 2 January 2018

Revised: 13 April 2018 - Accepted: 3 May 2018 - Published: 24 May 2018

\begin{abstract}
The Hydrology, Meteorology, and Complexity laboratory of École des Ponts ParisTech (hmco.enpc.fr) has made a data set of optical disdrometer measurements available that come from a campaign involving three collocated devices from two different manufacturers, relying on different underlying technologies (one Campbell Scientific PWS100 and two OTT Parsivel ${ }^{2}$ instruments). The campaign took place in JanuaryFebruary 2016 in the Paris area (France). Disdrometers provide access to information on the size and velocity of drops falling through the sampling area of the devices of roughly a few tens $\mathrm{of}^{2}$. It enables the drop size distribution to be estimated and rainfall microphysics, kinetic energy, or radar quantities, for example, to be studied further. Raw data, i.e. basically a matrix containing a number of drops according to classes of size and velocity, along with more aggregated ones, such as the rain rate or drop size distribution with filtering, are available.

Link to the data set: https://zenodo.org/record/1240168 (DOI: https://doi.org/10.5281/zenodo.1240168).
\end{abstract}

\section{Introduction}

Disdrometers enable not only information on the rainfall depth to be accessed as rain gauges, but also the size and velocity of falling drops. Their operational and research use is quickly increasing. Historically, impact disdrometers were the first widely used. They measure the noise generated by the impact of falling drops (Joss and Waldvogel, 1967). Now the most commonly used operationally are optical ones. They are made of a transmitter generating one or several laser sheet(s) and receiver(s) measuring either the occluded light (Loffler-Mang and Joss, 2000; Battaglia et al., 2010; Delahaye et al., 2006; Frasson et al., 2011) or the refracted light (Ellis et al., 2006) from the drops falling through a sampling area of roughly a few tens of $\mathrm{cm}^{2}$. The received signal is then processed to estimate the size (more precisely an equivolumic diameter, i.e. the diameter of a spherical drop with the same volume) and falling velocity of the hydrometeor. More sophisticated disdrometers, such as the 2-D video one, can also provide access to images of the falling hydrometeors (Kruger and Krajewski, 2002). Numerous studies have been carried out to compare the output of various types of disdrometers, usually with the more conventional rain gauges
(Miriovsky et al., 2004; Krajewski et al., 2006; Frasson et al., 2011; Thurai et al., 2011).

The drop size distribution (DSD), denoted $N(D)$, can be computed from disdrometer data. It is expressed in $\mathrm{m}^{-3} \mathrm{~mm}^{-1}$, and $N(D) \mathrm{d} D$ is the number of drops per unit volume (in $\mathrm{m}^{-3}$ ) with an equivolumic diameter between $D$ and $D+\mathrm{d} D$ (in mm). More precisely, a binned DSD will be obtained according to the classes of drop size (see Sect. 2.2 for a detailed explanation on how to retrieve it). It is actually possible to reconstruct many quantities relevant to researchers and practitioners from this DSD, since they are simply moments of the DSD; i.e. they can be written as weighed integrals of the DSD $\left(\int_{0}^{D_{\max }} f(D) N(D) \mathrm{d} D\right.$, where $f(D)$ is a function of the diameter $D$, typically a coefficient multiplied by a power of $D$ ). For instance, the DSD enables rainfall microphysics to be studied through, for example, the computation of quantities such as the total drop concentration or the mass weighed diameter characterizing the overall DSD (Pruppacher and Klett, 1997; Jaffrain and Berne, 2011). Such DSD information is for example needed for appropriate parametrization of numerical atmospheric models (Morrison et al., 2005). Using external information and assumptions about raindrop scattering properties, it is also possible to estimate, from the DSD, equivalent local pointwise radar 
quantities and hence study and possibly help improve radar rainfall retrieval algorithms. This approach has been implemented by numerous authors (Jaffrain and Berne, 2012a; Leinonen et al., 2012; Ryzhkov et al., 2005; Verrier et al., 2013; Gires et al., 2015). It should be mentioned that it relies on a strong unrealistic hypothesis, notably the homogeneity of the DSD within a radar bin (see Gires et al., 2018, for a discussion of the limitations of this approach). The DSD also enables the kinetic energy of rainfall to be computed, which is critical to the understanding and modelling of soil erosion (see van Dijk et al., 2002, for a review). Studies of the relation between rainfall intensity and kinetic energy using disdrometers have been carried out with actual rainfall (Angulo-Martínez and Barros, 2015; Angulo-Martínez et al., 2016) or artificial rainfall (Meshesha et al., 2016). The DSD also has an impact on the spread of crop disease (Huber and Gillespie, 1992), notably through the dispersal of pathogens through splashing (Walklate, 1989; Walklate et al., 1989).

Given the numerous potential applications of DSD data, the Hydrology, Meteorology, and Complexity laboratory of École des Ponts ParisTech (HM\&Co-ENPC) believes it is important to make the data available from a 2-month measurement campaign involving three collocated optical disdrometers from two manufacturers. Devices, data processing, and the campaign period are presented in Sect. 2. The corresponding database and available tools are presented in Sect. 3.

\section{Data and methods}

\subsection{Brief description of the devices' functioning}

The two devices are optical disdrometers operating with different principles. The goal of this section is only to briefly explain how the two devices work and highlight the main differences. The interested reader is then referred to papers and manufacturer documentation for more information.

The OTT Parsivel ${ }^{2}$ is made of a transmitter generating a laser sheet and a receiver aligned with the transmitter. When a drop falls through the sampling area of roughly $50 \mathrm{~cm}^{2}$, the laser beam is partially occluded and the intensity of the received signal decreases. Then the size (more precisely the equivolumic diameter) and fall velocity of the drop is assessed from the amplitude and duration of the decrease in received intensity. An ellipsoidal shape model for the drops with a standard relation between the axis ratio and the equivolumic diameter is assumed in the process. More details can be found in Battaglia et al. (2010) or in the device documentation (OTT, 2014).

The PWS100 configuration is different. It is made of a transmitter that generates four horizontal parallel light sheets, and two receptors which are not aligned with the transmitter. One is set on a vertical plane with an angle $\theta_{D}\left(=20^{\circ}\right)$ and the other is set on a horizontal plane with the same angle $\theta_{D}$. When a drop falls through the sampling area of size $S=40 \mathrm{~cm}^{2}$ a portion of the light is refracted and reaches the receptors. The signal received by each receptor contains four consecutive peaks associated with each laser sheet. From the delay between these peaks, the fall velocity of the hydrometeor is assessed. Then due to the refraction inside the drop, the signal will reach the vertical receiver slightly before the horizontal one. From this time shift the diameter of the drop can be estimated. Computations are carried out assuming a spherical shape, and a correction accounting for oblateness is then implemented. More details can be found in Ellis et al. (2006) or in the device documentation (Campbell-Scientific-Ltd, 2012). Actually the authors could improve the oblateness correction of the PWS100 rationale (Gires et al., 2017) and used it in previous studies (Gires et al., 2015).

\subsection{Available output and data processing}

The main output provided by both disdrometers is a matrix containing the number of drops recorded during the time step $\Delta t$ according to classes of equivolumic diameter (index $i$ and defined by a centre $D_{i}$ and a width $\Delta D_{i}$ expressed in mm) and fall velocity (index $j$ and defined by a centre $v_{j}$ and a width $\Delta v_{j}$ expressed in $\mathrm{m} \mathrm{s}^{-1}$ ). The measurement time step $\Delta t$ is equal to $30 \mathrm{~s}$ for this data set. The classes for each device are shown in Tables 1 and 2. In practice, the solution suggested by the authors to improve oblateness correction (Gires et al., 2017) simply consists in changing the centre and width defining the diameter classes for the PWS100. A new suggested table for rain drop was hence added to Table 1. Values and figures presented in this paper are obtained using the new correction. However it does not affect the retrieved matrices, meaning that it is up to the user to decide whether to use it or not. It should be mentioned that for the PWS100, data are measured only $9 / 10$ of the time; hence, to have comparable values, one should multiply the number of drops in each class for this device by 10/9. The underlying assumption behind this approach to compensate for the gap in data is homogeneity of the process at this temporal scale. It is a strong assumption that is not necessarily valid. All outputs presented in this paper and in the database take this correction into account. However it is not implemented in the raw data (basically the matrices) that have been made available.

From this matrix, it is then possible to compute the rain rate $\left(\right.$ in $\mathrm{mm} \mathrm{h}^{-1}$ ) for each time step as

$$
R=\frac{\pi}{6 \Delta t} \sum_{i, j} \frac{n_{i, j} D_{i}^{3}}{S_{\mathrm{eff}}\left(D_{i}\right)},
$$

where $S_{\text {eff }}\left(D_{i}\right)$ is the sampling area of the device (expressed in $\mathrm{mm}^{2}$ ) and $\Delta t$ is in $h$. In the data presented in the paper, $S_{\text {eff }}$ is slightly modified according to the drop size to account for edge effects for large drops. For the Parsivel ${ }^{2}$, we used $S_{\text {eff }}\left(D_{i}\right)=L\left(W-\frac{D_{i}}{2}\right)$, where $L=180 \mathrm{~mm}$ and $W=30 \mathrm{~mm}$ 
Table 1. Definition of the classes of particle size and velocity for the PWS100.

\begin{tabular}{|c|c|c|c|c|c|c|c|}
\hline \multicolumn{5}{|c|}{ Particle diameter classes } & \multicolumn{3}{|c|}{ Particle velocity classes } \\
\hline Class & $\begin{array}{r}\text { Diameter } \\
(\mathrm{mm})\end{array}$ & $\begin{array}{l}\text { Width } \\
(\mathrm{mm})\end{array}$ & $\begin{array}{r}\text { Corr. diam. } \\
(\mathrm{mm})\end{array}$ & $\begin{array}{r}\text { Corr. width } \\
(\mathrm{mm})\end{array}$ & Class & $\begin{array}{l}\text { Velocity } \\
\left(\mathrm{m} \mathrm{s}^{-1}\right)\end{array}$ & $\begin{array}{r}\text { Width } \\
\left(\mathrm{m} \mathrm{s}^{-1}\right)\end{array}$ \\
\hline 1 & 0.05 & 0.1 & 0.05 & 0.1 & 1 & 0.05 & 0.1 \\
\hline 2 & 0.15 & 0.1 & 0.15 & 0.1 & 2 & 0.15 & 0.1 \\
\hline 3 & 0.25 & 0.1 & 0.25 & 0.1 & 3 & 0.25 & 0.1 \\
\hline 4 & 0.35 & 0.1 & 0.35 & 0.1 & 4 & 0.35 & 0.1 \\
\hline 5 & 0.45 & 0.1 & 0.45 & 0.1 & 5 & 0.45 & 0.1 \\
\hline 6 & 0.55 & 0.1 & 0.55 & 0.1 & 6 & 0.55 & 0.1 \\
\hline 7 & 0.65 & 0.1 & 0.65 & 0.1 & 7 & 0.65 & 0.1 \\
\hline 8 & 0.75 & 0.1 & 0.75 & 0.1 & 8 & 0.75 & 0.1 \\
\hline 9 & 0.85 & 0.1 & 0.85 & 0.1 & 9 & 0.85 & 0.1 \\
\hline 10 & 0.95 & 0.1 & 0.95 & 0.1 & 10 & 0.95 & 0.1 \\
\hline 11 & 1.1 & 0.2 & 1.07 & 0.16 & 11 & 1.1 & 0.2 \\
\hline 12 & 1.3 & 0.2 & 1.24 & 0.16 & 12 & 1.3 & 0.2 \\
\hline 13 & 1.5 & 0.2 & 1.41 & 0.16 & 13 & 1.5 & 0.2 \\
\hline 14 & 1.7 & 0.2 & 1.58 & 0.16 & 14 & 1.7 & 0.2 \\
\hline 15 & 1.9 & 0.2 & 1.74 & 0.16 & 15 & 1.9 & 0.2 \\
\hline 16 & 2.2 & 0.4 & 1.99 & 0.32 & 16 & 2.2 & 0.4 \\
\hline 17 & 2.6 & 0.4 & 2.31 & 0.31 & 17 & 2.6 & 0.4 \\
\hline 18 & 3.0 & 0.4 & 2.62 & 0.31 & 18 & 3.0 & 0.4 \\
\hline 19 & 3.4 & 0.4 & 2.93 & 0.3 & 19 & 3.4 & 0.4 \\
\hline 20 & 3.8 & 0.4 & 3.24 & 0.3 & 20 & 3.8 & 0.4 \\
\hline 21 & 4.4 & 0.8 & 3.68 & 0.58 & 21 & 4.4 & 0.8 \\
\hline 22 & 5.2 & 0.8 & 4.26 & 0.55 & 22 & 5.2 & 0.8 \\
\hline 23 & 6.0 & 0.8 & 4.8 & 0.52 & 23 & 6.0 & 0.8 \\
\hline 24 & 6.8 & 0.8 & 5.3 & 0.48 & 24 & 6.8 & 0.8 \\
\hline 25 & 7.6 & 0.8 & 5.77 & 0.44 & 25 & 7.6 & 0.8 \\
\hline 26 & 8.8 & 1.6 & 6.4 & 0.76 & 26 & 8.8 & 1.6 \\
\hline 27 & 10.4 & 1.6 & 7.07 & 0.57 & 27 & 10.4 & 1.6 \\
\hline 28 & 12.0 & 1.6 & 7.54 & 0.36 & 28 & 12.0 & 1.6 \\
\hline 29 & 13.6 & 1.6 & 7.78 & 0.12 & 29 & 13.6 & 1.6 \\
\hline 30 & 15.2 & 1.6 & & & 30 & 15.2 & 1.6 \\
\hline 31 & 17.6 & 3.2 & & & 31 & 17.6 & 3.2 \\
\hline 32 & 20.8 & 3.2 & & & 32 & 20.8 & 3.2 \\
\hline 33 & 24.0 & 3.2 & & & 33 & 24.0 & 3.2 \\
\hline 34 & 27.2 & 3.2 & & & 34 & 27.2 & 3.2 \\
\hline
\end{tabular}

are respectively the length and width of the sampling area $\left(L W=54 \mathrm{~cm}^{2}\right)$ (OTT, 2014). Due to its different configuration, the PWS100 is not affected by this issue and a constant $S_{\text {eff }}$ equal to $40 \mathrm{~cm}^{2}$ is considered (Campbell-Scientific-Ltd, 2012). Again the user has access to the raw data (i.e. the matrix), so he/she can decide whether to use this correction.

A discrete DSD, $N\left(D_{i}\right)$, for a given time step can also directly be computed from the raw matrix as

$N\left(D_{i}\right)=\frac{1}{S_{\mathrm{eff}}\left(D_{i}\right) \Delta D_{i} \Delta t} \sum_{j} \frac{n_{i, j}}{v_{j}}$.

$N\left(D_{i}\right) \Delta D_{i}$ gives the number of drops with a diameter in the class $i$ per unit volume (in $\mathrm{m}^{-3}$ ).

For the data presented in this paper, we also included a filter suggested by various authors (Kruger and Krajewski,
2002; Thurai and Bringi, 2005; Jaffrain and Berne, 2012b) to remove drops that, according to their size and velocity, are considered to be non-meteorological measurements. Practically, hydrometeors whose velocity differs more than $60 \%$ from the terminal fall velocity expected from its diameter and Beard's formula (Beard, 1977) are removed. Again, this filter is not implemented in the available raw matrices, so users are obviously free to use it or not.

The temperature in ${ }^{\circ} \mathrm{C}$ is also provided by both devices at the same time step. For the Parsivel ${ }^{2}$ instruments, the resolution of the sensor is only $1^{\circ}$. For the PWS100, there is a dedicated sensor (CS215, with a $0.01^{\circ}$ resolution) in the meteorological shelter, visible on the mast of the PWS100 in Fig. 1. 


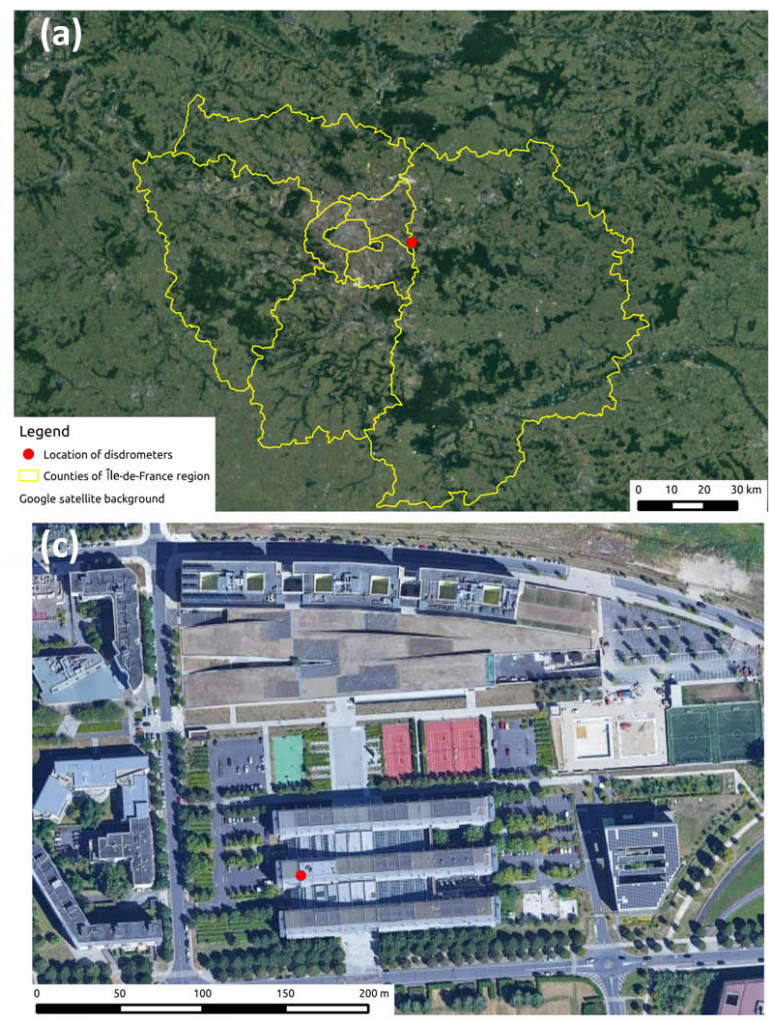

(b)

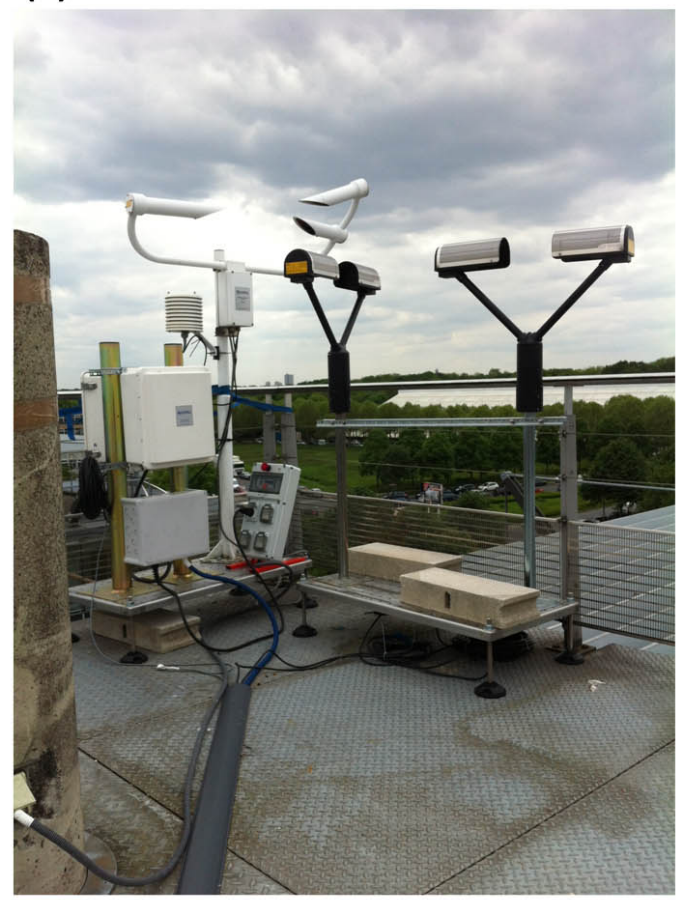

Figure 1. Location of the disdrometers in the Paris area (a), on the roof of the Carnot building (b) and at the ENPC campus (c).

\subsection{Measurement period}

The three disdrometers whose data are available in this paper were located on the roof of the Carnot building of the École des Ponts ParisTech campus, in the Paris area (Fig. 1). They are part of the TARANIS observatory (exTreme and multi-scAle RAiNdrop parIS observatory, Gires et al., 2015) of the Fresnel Platform of École des Ponts ParisTech (https://hmco.enpc.fr/portfolio-archive/ fresnel-platform/, last access: 18 May 2018). They are located not far from the edge of the roof. As it can be seen in Fig. 1, the two Parsivel ${ }^{2}$ instruments (black devices) were oriented perpendicularly to check if dominant wind had a strong influence on the measurements, and it was found that it did not. For this campaign, denoted by "Carnot_1", the data were collected during the months of January and February 2016, during which there were very few missing data. More precisely, over these 60 days, there are 2398, 2399, and 3180 missing times steps (roughly 20 to $26 \mathrm{~h}$ ) for the Parsivel ${ }^{2}$ no. 1, the Parsivel $^{2}$ no. 2, and the PWS100 respectively. For the Parsivel ${ }^{2}$ instruments, this corresponds to dry periods during which the data were uploaded from the computer collecting the data simultaneously for the three devices. The additional ones for the PWS100 (which are spread over the period) correspond to time steps during which the retrieval was not possible for unknown reasons. It should be mentioned that during these additional time steps, both Parsivel ${ }^{2}$ instru- ments collected less than $0.1 \mathrm{~mm}$ of rain. Basically no snow was recorded during this period, except a little on 18 February. Snow can be identified through the recorded fall velocity of the hydrometeors. Indeed, for a similar size, snowflakes will fall much slower than rain drops. The temperature which is recorded by both devices (with a greater resolution for the PWS100, as previously discussed) can also be helpful.

Figure 2 displays the temporal evolution of the rain rate and cumulative rainfall depth during the 2-month period. It can be seen that despite the correction implemented, the total rainfall depth for PWS100 $(104 \mathrm{~mm})$ remains significantly superior to the one measured with Parsivel $^{2}$ no. 1 $(86 \mathrm{~mm})$ and Parsivel $^{2}$ no. $2(84 \mathrm{~mm})$. Such total depths are common for the period and the area. Indeed, according to Meteo France, the French official meteorological agency, the climatological average over these 2 months is $92.2 \mathrm{~mm}$ in Paris (18.25 km west of the disdrometers' location) and $102.7 \mathrm{~mm}$ in Melun (32 km south of the disdrometers' location) (source http://www.meteofrance.com/climat, last access: 18 May 2018). No extreme events were recorded; i.e. the maximums observed at both 5 and $30 \mathrm{~min}$ have return periods smaller than 1 month. Such "common" events are notably relevant for urban water managers because they correspond to ones for which they should be able to fully decontaminate storm water before release in the natural environ- 
ment. Furthermore, over this range of values, the devices are expected to be reliable.

\section{Database}

This section contains a description of the database content, along with some available scripts. The database is organized as follows:

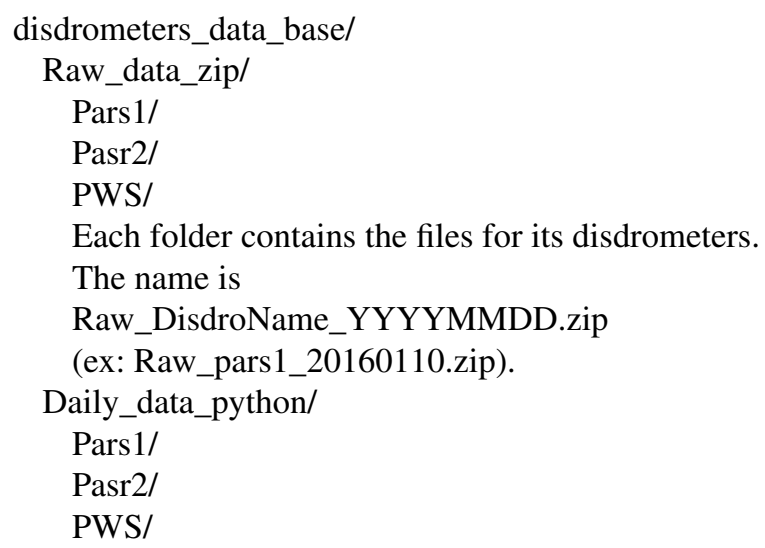

Each folder contains the files for its disdrometers.

The name is

Raw_DisdroName_YYYYMMDD.zip

(ex: Raw_pars1_20160110.zip).

Daily_data_python/

Pars1/

Pasr2/

PWS/

Each folder contains the files for its disdrometers.

The name is

DisdroName_raw_data_YYYYMMDD.csv

(ex: Pars1_raw_data_20160110.npy).

Daily_data_csv/

Pars1/

Pasr2/

PWS/

Each folder contains the files for its disdrometers.

The name is

DisdroName_daily_data_YYYYMMDD.csv

(ex: Pars1_daily_data_20160110.npy).

Calendars/

Data_5_min/ (one file per day ex:

R_5_min_Carnot_1_2016_01_10_00_00_00_

_2016_01_10_23_59_30.csv)

Data_30_sec/ (one file per day ex:

R_30_sec_Carnot_1_2016_01_10_00_00_00_

_2016_01_10_23_59_30.csv)

Quicklooks/ (one file per day ex:

Quicklook_Carnot_1_2016_01_10_00_00_00_ _2016_01_10_23_59_30.png

Calendar_data_5_min_Carnot_1.html

Calendar_data_30_sec_Carnot_1.html

Calendar_Carnot_1.html

Python_scripts/

It contains the Python scripts (and associated files) to generate and use this database.

Read_me.txt

It contains a short description of the Taranis database.
Table 2. Definition of the classes of particle size and velocity for the Parsivel $^{2}$.

\begin{tabular}{|c|c|c|c|c|c|}
\hline \multicolumn{3}{|c|}{ Particle diameter classes } & \multicolumn{3}{|c|}{ Particle velocity classes } \\
\hline Class & $\begin{array}{r}\text { Diameter } \\
(\mathrm{mm})\end{array}$ & $\begin{array}{l}\text { Width } \\
(\mathrm{mm})\end{array}$ & Class & $\begin{array}{l}\text { Velocity } \\
\left(\mathrm{ms}^{-1}\right)\end{array}$ & $\begin{array}{r}\text { Width } \\
\left(\mathrm{m} \mathrm{s}^{-1}\right)\end{array}$ \\
\hline 1 & 0.062 & 0.125 & 1 & 0.05 & 0.1 \\
\hline 2 & 0.187 & 0.125 & 2 & 0.15 & 0.1 \\
\hline 3 & 0.312 & 0.125 & 3 & 0.25 & 0.1 \\
\hline 4 & 0.437 & 0.125 & 4 & 0.35 & 0.1 \\
\hline 5 & 0.562 & 0.125 & 5 & 0.45 & 0.1 \\
\hline 6 & 0.687 & 0.125 & 6 & 0.55 & 0.1 \\
\hline 7 & 0.812 & 0.125 & 7 & 0.65 & 0.1 \\
\hline 8 & 0.937 & 0.125 & 8 & 0.75 & 0.1 \\
\hline 9 & 1.062 & 0.125 & 9 & 0.85 & 0.1 \\
\hline 10 & 1.187 & 0.125 & 10 & 0.95 & 0.1 \\
\hline 11 & 1.375 & 0.25 & 11 & 1.1 & 0.2 \\
\hline 12 & 1.625 & 0.25 & 12 & 1.3 & 0.2 \\
\hline 13 & 1.875 & 0.25 & 13 & 1.5 & 0.2 \\
\hline 14 & 2.125 & 0.25 & 14 & 1.7 & 0.2 \\
\hline 15 & 2.375 & 0.25 & 15 & 1.9 & 0.2 \\
\hline 16 & 2.75 & 0.5 & 16 & 2.2 & 0.4 \\
\hline 17 & 3.25 & 0.5 & 17 & 2.6 & 0.4 \\
\hline 18 & 3.75 & 0.5 & 18 & 3.0 & 0.4 \\
\hline 19 & 4.25 & 0.5 & 19 & 3.4 & 0.4 \\
\hline 20 & 4.75 & 0.5 & 20 & 3.8 & 0.4 \\
\hline 21 & 5.5 & 1.0 & 21 & 4.4 & 0.8 \\
\hline 22 & 6.5 & 1.0 & 22 & 5.2 & 0.8 \\
\hline 23 & 7.5 & 1.0 & 23 & 6.0 & 0.8 \\
\hline 24 & 8.5 & 1.0 & 24 & 6.8 & 0.8 \\
\hline 25 & 9.5 & 1.0 & 25 & 7.6 & 0.8 \\
\hline 26 & 11.0 & 2.0 & 26 & 8.8 & 1.6 \\
\hline 27 & 13.0 & 2.0 & 27 & 10.4 & 1.6 \\
\hline 28 & 15.0 & 2.0 & 28 & 12.0 & 1.6 \\
\hline 29 & 17.0 & 2.0 & 29 & 13.6 & 1.6 \\
\hline 30 & 19.0 & 2.0 & 30 & 15.2 & 1.6 \\
\hline 31 & 21.5 & 3.0 & 31 & 17.6 & 3.2 \\
\hline 32 & 24.5 & 3.0 & 32 & 20.8 & 3.2 \\
\hline
\end{tabular}

\subsection{Calendars}

This folder contains a .html file ("Calendar_Carnot_1.html") providing an overview of the measurement campaign. Figure 3 displays a snapshot of it. It enables the most interesting days to be quickly identified according to the aims of the user. By clicking on any day, one can access a quicklook of the corresponding day. The links are relative ones, so the file should be located as indicated in the above structure for the links to work. Figure 4 shows an example. This quicklook provides an overview of the day according to the measurements of the three disdrometers with (1) the temporal evolution of the rain rate (upper left); (2) the temporal evolution of the cumulative rainfall depth (upper right); (3) the temporal evolution of the DSD $N(D)$ (middle left); (4) indication of the missing data if there are any (middle right; in the example there are two missing time steps for the PWS100 and none 

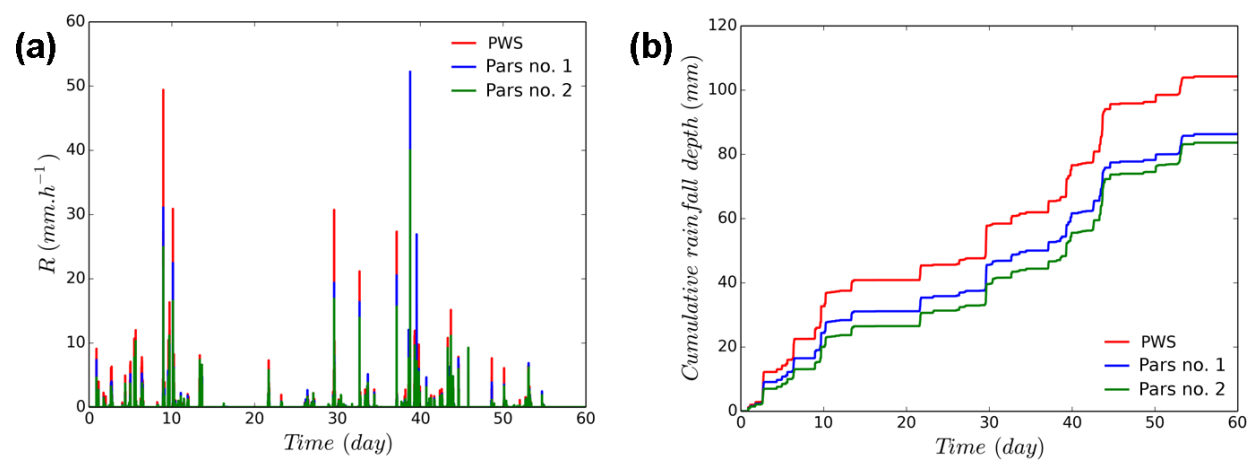

Figure 2. Temporal evolution of the rain rate and cumulative rainfall depth over the months of the measurement campaign for the three disdrometers.

\section{HMCO disdrometers on Carnot building roof on ENPC campus \\ Quicklooks}

\begin{tabular}{|c|c|c|c|c|c|c|}
\hline \multirow{2}{*}{\multicolumn{7}{|c|}{$\begin{array}{r}\text { Monday Tuesday Wednesday Thursday Fr } \\
\text { January } 2016\end{array}$}} \\
\hline & & & & & & \\
\hline \multirow{2}{*}{$\underline{4}$} & & & & \multirow{2}{*}{$\begin{array}{l}\underline{1} \\
\underline{8}\end{array}$} & \multirow{2}{*}{$\frac{\underline{2}}{\underline{9}}$} & \multirow{2}{*}{$\underline{\underline{3}}$} \\
\hline & $\underline{5}$ & $\underline{6}$ & $\underline{7}$ & & & \\
\hline$\underline{11}$ & $\underline{12}$ & $\underline{13}$ & $\underline{14}$ & $\underline{15}$ & $\underline{16}$ & $\underline{17}$ \\
\hline$\underline{18}$ & $\underline{19}$ & $\underline{20}$ & $\underline{21}$ & $\underline{22}$ & $\underline{23}$ & $\underline{24}$ \\
\hline$\underline{25}$ & $\underline{26}$ & 27 & $\underline{28}$ & $\underline{29}$ & 30 & $\underline{31}$ \\
\hline \multicolumn{7}{|c|}{ February 2016} \\
\hline$\underline{1}$ & $\underline{2}$ & $\underline{3}$ & $\underline{4}$ & $\underline{5}$ & $\underline{6}$ & $\underline{7}$ \\
\hline$\underline{8}$ & $\underline{9}$ & $\underline{10}$ & $\underline{11}$ & $\underline{12}$ & $\underline{13}$ & $\underline{14}$ \\
\hline$\underline{15}$ & $\underline{16}$ & $\underline{17}$ & $\underline{18}$ & $\underline{19}$ & $\underline{20}$ & $\underline{21}$ \\
\hline$\underline{22}$ & $\underline{23}$ & $\underline{24}$ & $\underline{25}$ & $\underline{26}$ & $\underline{27}$ & $\underline{28}$ \\
\hline
\end{tabular}

\section{Colour code}

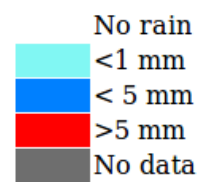

Figure 3. Snapshot of the calendar summarizing the January-February 2016 campaign on the roof of the Carnot building.

for the Parsivel ${ }^{2}$ instruments); (5) a map of the number of drops according to the velocity and size classes (middle right; the solid black line is the curve corresponding to the relation between the terminal fall velocity of drops as a function of their equivolumic diameter obtained by Lhermitte, 1988) (middle right); (6) $N(D) D^{3}$ as a function of $D$ (lower left; it was chosen to plot $N(D) D^{3}$ and not simply $N(D)$ because it is proportional to the volume of rain obtained according to the drop diameter, hence providing the reader with a greater immediate insight into the influence of the various drop sizes on the observed rainfall event); and (7) the temporal evolution of the temperature (lower right). The quicklooks are stored in the folder Quicklooks/ and can be accessed directly there. Their names are "Quicklook_Carnot_1_", followed by the date of the start and end of the corresponding day, in a string format. For example, the one displayed in Fig. 4 is called "Quicklook_Carnot_1_2016_01_10_00_00_00_ _2016_01_10_23_59_30.png". Local times are used.

The file "Calendar_R_30_sec_Carnot_1.html" is a calendar similar to the previous one, except that the links provide access to the rain rates (in $\mathrm{mm} \mathrm{h}^{-1}$ ) for each $30 \mathrm{~s}$ time step of the day in .csv format. The files are located in the folder Data_30_second/ and named in a similar way to the quicklooks (for ex- 

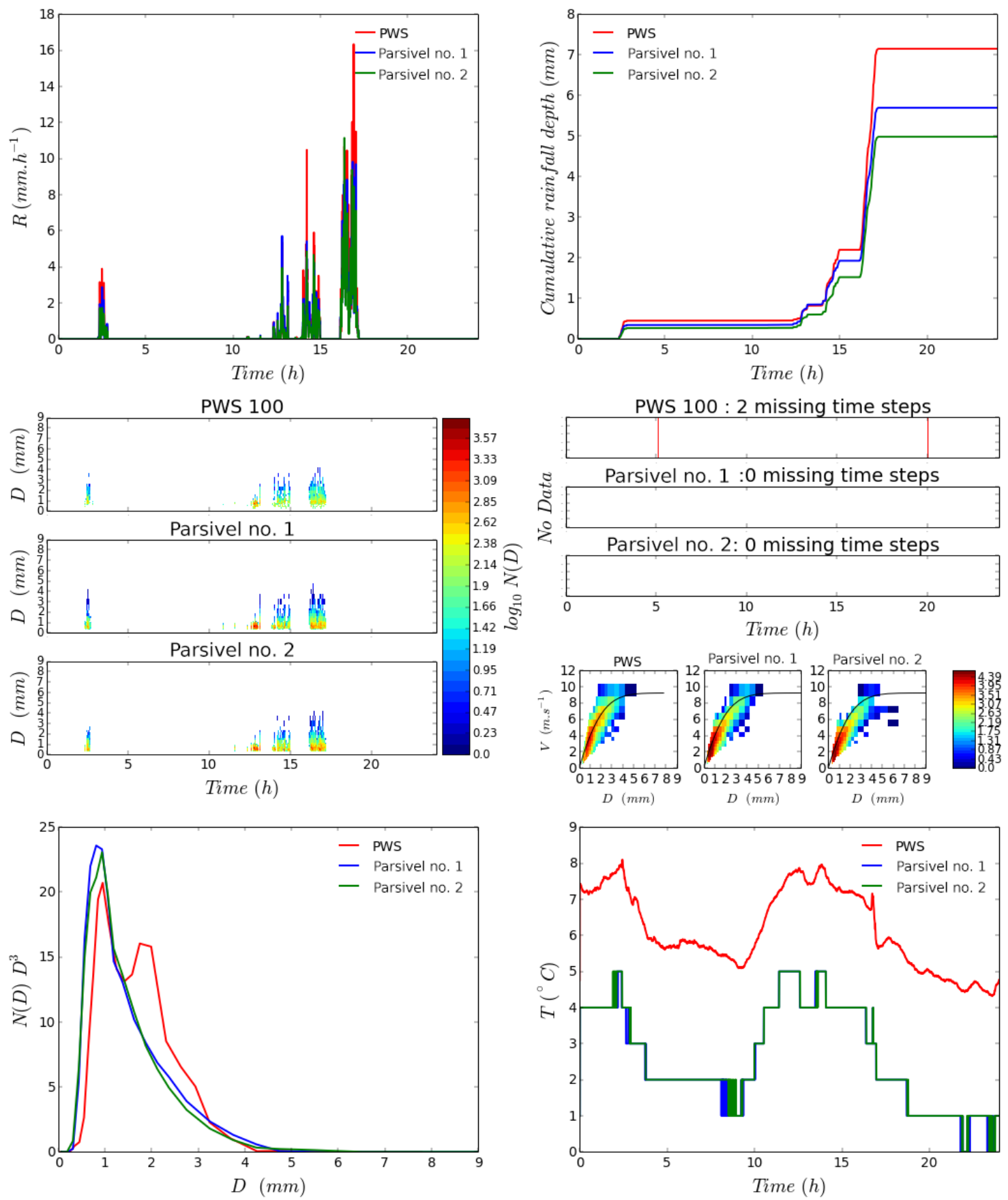

Figure 4. Quicklook of the disdrometer data available on 10 January 2016.

ample, "R_30_sec_Carnot_1_2016_01_10_00_00_00_ _2016_01_10_23_59_30.csv"). The format is as follows: (i) there is one line per $30 \mathrm{~s}$ time step starting on YYYYMM-DD 00:00:00 (local time). (ii) In each line, values for the three disdrometers are separated with semicolons, and the order is PWS, Pars no. 1, Pars no. 2. (iii) Missing data are denoted by "nan" (which stands for "not a number").
The file "Calendar_R_5_min_Carnot_1.html" is a calendar similar to the previous one, except that the links provide access to the rain rates (in $\mathrm{mm} \mathrm{h}^{-1}$ ) for each $5 \mathrm{~min}$ time step of the day in .csv format. The files are located in the folder "Data_5_min" and are named in a similar way to the quicklooks (for example, $\quad$ R_5_min_Carnot_1_2016_01_10_00_00_00_ 
_2016_01_10_23_59_30.csv"). The format is the same as for the $30 \mathrm{~s}$ time step data.

\subsection{Daily_data_csv/}

This folder contains a folder for each of the three disdrometers. Each of these folders contains daily files with the most relevant data measured by the device, i.e. the full matrix of drops according to classes of size and velocity and the temperature. A file is typically called "Pars1_daily_data_20160110.csv", meaning the disdrometer name and day corresponding to the data are easily visible for the user. The format is as follows: (i) there is one line per time step. (ii) Each line includes the date (YYYY-MM-DD HH:MM:SS), the number of drops per class of velocity and size (first size class - first velocity class, first size class - second velocity class, ..., second size class - first velocity class...), separated by commas $(34 \times 34$ classes for PWS data and $32 \times 32$ classes for Parsivel data), and temperature (in ${ }^{\circ} \mathrm{C}$ ), for example, "2016-0110 17:27:00;0.0,0.0,0.0....., $0.0 ; 7$ ”. (iii) Missing data are indicated by "nan". The reader should be reminded here that the number of drops for each class should be multiplied by $10 / 9$ for the PWS100 because it only measures $9 / 10$ of the time. These files are text files that can be read by any software.

\subsection{Daily_data_python/}

This folder contains a folder for each of the three disdrometers. Each of these folders contains a daily file as a list of the data collected by the devices. It is stored in .npy format, readable with the help of Python 3. The precise content of the list according to the device can be found in the "Read_me_v1.txt" file. These files are used by the Python scripts which have been made available.

\subsection{Raw_data_zip/}

This folder contains a folder for each of the three disdrometers. Each of these folders contains a zip file for each day. This .zip file contains the data directly collected from the disdrometer. There is one text file for each $30 \mathrm{~s}$ time step. The precise format of these fields can be found in the Python scripts in the heading of the corresponding functions. This corresponds to the raw data. These data have been made available for expert users, but in practice it is believed that the .csv file or the Python scripts should be sufficient for most users.

\subsection{Python_scripts/}

This section contains some Python scripts that can be used to carry out some initial analysis and data treatment with the database. The tools are located in the script "Tools_data_base_use_v3.py". The main functions are given as follows (only a short description is given here - more details, including a precise description of the inputs and outputs of the functions, are provided as comments in each script):

- Quicklook_and_R_series_generation_Carnot_1: generating a quicklook image and the corresponding $30 \mathrm{~s}$ and 5 min rain rate time series for a given rainfall event for the Carnot_1 campaign;

- extracting_one_event_Carnot_1: reading daily.npy files and generating three lists (one for each disdrometer) containing all the data that can be analysed for the Carnot_1 campaign;

- exporting_full_matrix: reading daily.npy files and exporting full matrix in .csv files for a given disdrometer and event;

- exporting_R: reading daily.npy files and exporting R in .csv files for a given disdrometer and event;

- exporting_T: reading daily.npy files and exporting $\mathrm{T}$ in .csv files for a given disdrometer and event.

Commented examples of the use of the functions can be found in the scripts under "Example_of_use_data_base_Carnot_1.py". Note that Python 3 (www.python.org, last access: 18 May 2018) is required because the .npy files containing the data were saved using Python 3.

\section{Data availability}

The $30 \mathrm{~s}$ disdrometer data from a 2-month measurement campaign with collocated devices in the Paris area are presented in this paper. Raw data, along with Python-formatted data with corresponding scripts, are described. The Hydrology, Meteorology, and Complexity laboratory of École des Ponts ParisTech (HM\&Co-ENPC) has made this data set available at http://doi.org/10.5281/zenodo.1240168. The following citations should be used for every use of the data.

- For this paper: Gires, A., Tchiguirinskaia, I., and Schertzer, D.: Two months of disdrometer data in the Paris area, Earth Syst. Sci. Data, 10, 941-950, https://doi.org/10.5194/essd-10-941-2018, 2018.

- For the database: Gires, Auguste, Tchiguirinskaia, Ioulia, and Schertzer, Daniel. (2017). Data for "Two months of disdrometer data in the Paris area" (Version v2 of the dataset) [Data set]. Zenodo. http://doi.org/10. 5281/zenodo.1240168.

This data set is available for download free of charge. License terms apply. These disdrometers and others similar ones have been used in other campaigns by HM\&Co and are still collecting data. Regular updates of their status along with updates of the database are to be provided through 
the lab's website (hmco.enpc.fr). The web page https:// hmco.enpc.fr/portfolio-archive/taranis-observatory/ (last access: 18 May 2018) already contains links to the summary calendars for past and ongoing measurement campaigns (daily updates).

Competing interests. The authors declare that they have no conflict of interest.

Acknowledgements. The authors greatly acknowledge partial financial support from the Chair of Hydrology for Resilient Cities (endowed by Veolia) of the École des Ponts ParisTech, EU NEW INTERREG IV RainGain Project (www.raingain.eu, last access: 18 May 2018), EU Climate KIC Blue Green Dream (www.bgd. org.uk, last access: 18 May 2018), and the Île-de-France region RadX@IdF Project.

The authors thank Serge Botton (from the Departement Positionnement Terrestre et Spatial of the ENSG) for facilitating access to the roof where the disdrometers are installed.

Edited by: David Carlson

Reviewed by: two anonymous referees

\section{References}

Angulo-Martínez, M. and Barros, A.: Measurement uncertainty in rainfall kinetic energy and intensity relationships for soil erosion studies: An evaluation using PARSIVEL disdrometers in the Southern Appalachian Mountains, Geomorphology, 228, 28-40, https://doi.org/10.1016/j.geomorph.2014.07.036, 2015.

Angulo-Martínez, M., Beguería, S., and Kyselý, J.: Use of disdrometer data to evaluate the relationship of rainfall kinetic energy and intensity (KE-I), Sci. Total Environ., 568, 83-94, https://doi.org/10.1016/j.scitotenv.2016.05.223, 2016.

Battaglia, A., Rustemeier, E., Tokay, A., Blahak, U., and Simmer, C.: PARSIVEL Snow Observations: A Critical Assessment, J. Atmos. Ocean. Tech., 27, 333-344, 2010.

Beard, K. V.: Terminal velocity adjustment for cloud and precipitation aloft, J. Atmos. Sci., 34, 1293-1298, 1977.

Campbell-Scientific-Ltd: PWS100 Present Weather Sensor, User Guide, 2012.

Delahaye, J.-Y., Barthès, L., Golé, P., Lavergnat, J., and Vinson, J.: A dual-beam spectropluviometer concept, Measurement and Parameterization of Rainfall Microstructure, 328, 110-120, https://doi.org/10.1016/j.jhydrol.2005.11.048, 2006.

Ellis, R. A., Sandford, A. P., Jones, G. E., Richards, J., Petzing, J., and Coupland, J. M.: New laser technology to determine present weather parameters, Meas. Sci. Technol., 17, 1715-1722, 2006.

Frasson, R. P. D. M., da Cunha, L. K., and Krajewski, W. F.: Assessment of the Thies optical disdrometer performance, Atmos. Res., 101, 237-255, 2011.

Gires, A., Tchiguirinskaia, I., and Schertzer, D.: Multifractal comparison of the outputs of two optical disdrometers, Hydrolog. Sci. J., 6, 1641-1651, https://doi.org/10.1080/02626667.2015.1055270, 2015.
Gires, A., Tchiguirinskaia, I., and Schertzer, D.: Method and device for measuring the equivalent diameter of a water drop, European Patent Office (Application nb. EP3246692), 2017.

Gires, A., Tchiguirinskaia, I., and Schertzer, D.: Pseudo-radar algorithms with two extremely wet months of disdrometer data in the Paris area, Atmos. Res., 203, 216-230, https://doi.org/10.1016/j.atmosres.2017.12.011., 2018.

Huber, L. and Gillespie, T.: Modeling Leaf Wetness in Relation to Plant Disease Epidemiology, Annu. Rev. Phytopathol., 30, 553-577, https://doi.org/10.1146/annurev.py.30.090192.003005, 1992.

Jaffrain, J. and Berne, A.: Experimental Quantification of the Sampling Uncertainty Associated with Measurements from PARSIVEL Disdrometers, J. Hydrometeorol., 12, 352-370, 2011.

Jaffrain, J. and Berne, A.: Influence of the Subgrid Variability of the Raindrop Size Distribution on Radar Rainfall Estimators, J. Appl. Meteorol. Clim., 51, 780-785, https://doi.org/10.1175/JAMC-D-11-0185.1, 2012a.

Jaffrain, J. and Berne, A.: Quantification of the Small-Scale Spatial Structure of the Raindrop Size Distribution from a Network of Disdrometers, J. Appl. Meteorol. Clim., 51, 941-953, https://doi.org/10.1175/JAMC-D-11-0136.1, 2012b.

Joss, J. and Waldvogel, A.: Ein spektrograph fur nieder chlagstropfen mit automatischer auswertung (A spectrograph for raindrops with automatic interpretation), Pure Appl. Geophys. Rev. A., 68, 240-246, 1967.

Krajewski, W. F., Kruger, A., Caracciolo, C., Golé, P., Barthes, L., Creutin, J.-D., Delahaye, J.-Y., Nikolopoulos, E. I., Ogden, F., and Vinson, J.-P.: DEVEX-disdrometer evaluation experiment: Basic results and implications for hydrologic studies, Adv. Water Resour., 29, 311-325, 2006.

Kruger, A. and Krajewski, W. F.: Two-Dimensional Video Disdrometer: A Description, J. Atmos. Ocean. Tech., 19, 602-617, https://doi.org/10.1175/1520 0426(2002)019<0602:TDVDAD>2.0.CO;2, 2002.

Leinonen, J., Moisseev, D., Leskinen, M., and Petersen, W. A.: A Climatology of Disdrometer Measurements of Rainfall in Finland over Five Years with Implications for Global Radar Observations, J. Appl. Meteorol. Clim., 51, 392-404, https://doi.org/10.1175/JAMC-D-11-056.1, 2012.

Lhermitte, R. M.: Cloud and precipitation remote sensing at 94 GHz, Geoscience and Remote Sensing, IEEE T., 26, 207-216, 1988.

Loffler-Mang, M. and Joss, J.: An Optical Disdrometer for Measuring Size and Velocity of Hydrometeors, J. Atmos. Ocean. Tech., 17, 130-139, https://doi.org/10.1175/15200426(2000)017<0130:AODFMS>2.0.CO;2, 2000.

Meshesha, D. T., Tsunekawa, A., Tsubo, M., Haregeweyn, N., and Tegegne, F.: Evaluation of kinetic energy and erosivity potential of simulated rainfall using Laser Precipitation Monitor, CATENA, 137, 237-243, https://doi.org/10.1016/j.catena.2015.09.017, 2016.

Miriovsky, B. J., Bradley, A. A., Eichinger, W. E., Krajewski, W. F., Kruger, A., Nelson, B. R., Creutin, J.D., Lapetite, J.-M., Lee, G. W., Zawadzki, I., and Ogden, F. L.: An Experimental Study of Small-Scale Variability of Radar Reflectivity Using Disdrometer Observations, J. Appl. Meteorol., 43, 106-118, https://doi.org/10.1175/15200450(2004)043<0106:AESOSV>2.0.CO;2, 2004. 
Morrison, H., Curry, J. A., and Khvorostyanov, V. I.: A New Double-Moment Microphysics Parameterization for Application in Cloud and Climate Models. Part I: Description, J. Atmos. Sci., 62, 1665-1677, https://doi.org/10.1175/JAS3446.1, 2005.

OTT: Operating instructions, Present Weather Sensor OTT Parsivel2, 2014.

Pruppacher, H. and Klett, J.: Microphysics of Clouds and Precipitation, no. 18 in Atmospheric and Oceanographic Sciences Library, Springer Netherlands, https://doi.org/10.1007/978-0-306-481000, 1997.

Ryzhkov, A. V., Giangrande, S. E., and Schuur, T. J.: Rainfall Estimation with a Polarimetric Prototype of WSR-88D, J. Appl. Meteorol., 44, 502-515, https://doi.org/10.1175/JAM2213.1, 2005.

Thurai, M. and Bringi, V. N.: Drop Axis Ratios from a 2D Video Disdrometer, J. Atmos. Ocean. Tech., 22, 966-978, https://doi.org/10.1175/JTECH1767.1, 2005.

Thurai, M., Petersen, W. A., Tokay, A., Schultz, C., and Gatlin, P.: Drop size distribution comparisons between Parsivel and 2-D video disdrometers, Adv. Geosci., 30, 3-9, https://doi.org/10.5194/adgeo-30-3-2011, 2011. van Dijk, A. I. J. M., Bruijnzeel, L. A., and Rosewell, C. J.: Rainfall intensity-kinetic energy relationships: a critical literature appraisal, J. Hydrol., 261, 1-23, https://doi.org/10.1016/S00221694(02)00020-3, 2002.

Verrier, S., Barthès, L., and Mallet, C.: Theoretical and empirical scale dependency of Z-R relationships: Evidence, impacts, and correction, J. Geophys. Res.-Atmos., 118, 7435-7449, https://doi.org/10.1002/jgrd.50557, 2013.

Walklate, P. J.: Vertical dispersal of plant pathogens by splashing. Part I: the theoretical relationship between rainfall and upward rain splash, Plant Pathol., 38, 56-63, https://doi.org/10.1111/j.1365-3059.1989.tb01427.x, 1989.

Walklate, P. J., McCartney, H. A., and Fitt, B. D. L.: Vertical dispersal of plant pathogens by splashing. Part II: experimental study of the relationship between raindrop size and the maximum splash height, Plant Pathol., 38, 64-70, https://doi.org/10.1111/j.13653059.1989.tb01428.x, 1989. 